\title{
Epidemiology of tsetse flies in the transmission of trypanosomiasis: technical review of The Gambia experience
}

\author{
Alpha KARGBO ${ }^{1,2^{*}}$ and Rex A. KUYE ${ }^{3}$ \\ ${ }^{l}$ WASCAL-Graduate Research Program in Climate Change and Biodiversity, Universite Felix Houphouet- \\ Boigny, BP V34, Abidjan, Cote d' Ivoire. \\ ${ }^{2}$ Department of Physical and Natural Sciences, University of The Gambia, Brikama Campus, \\ P. O Box 3530, Serrekunda, The Gambia. \\ ${ }^{3}$ Department Public Health and environmental, School of Medicine and Allied Health Science, University of \\ The Gambia, Brikama Campus, \\ P. O Box 3530, Serrekunda, The Gambia. \\ *Corresponding author; E-mail: akargbo@utg.edu.gm ; Tel: 0022502585994/+2203854579
}

\begin{abstract}
Climate change has posed serious health threats on both man and animals. This ranges from effects of progressive temperature rises from global warming to extreme weather events and anthropogenic activities and this has affected insect-vector distributions worldwide. Tsetse fly species transmit Trypanosomes but relative significance depends largely on the strength of their interactions with susceptible hosts. Tsetse flies are the main vectors of Trypanosomiasis and their existence pose a threat to the survival of cattle, small ruminates and equines in The Gambia. It is known to be one of the most vital parasitic diseases affecting livestock productivity in The Gambia and equines are very susceptible. Central River Region is mainly infested with the tsetse fly Glossina morsitan submorsitan a major vector of Trypanosomiasis among animals in the country and it is mainly found in dry, canopied, savannah woodland. Glossina palpalis is also present, but are more limited to riverine vegetation in the area. This work seeks to show the havoc caused by trypanosomiasis and the urgency for more studies to investigate the patterns of transmission of this disease especially in the context of climate change in other for a better control program for this zoonosis in The Gambia.
\end{abstract}

(c) 2020 International Formulae Group. All rights reserved.

Keywords: Climate Change, Glossina, Trypanosome, Cattle, Equine.

\section{INTRODUCTION}

Tsetse flies are well-known vectors of Trypanosomiasis. They signify a threat to public health and economy in sub-Saharan Africa. Despite these concerns, information on the temporal and spatial dynamics of Tsetse and Trypanosomes still remain limited and may be a motive that control strategies are less effective (Nnko et al., 2016). Trypanosomiasis is known as a zoonotic disease with a life cycle involving an insect and a mammalian host. Most herbivorous and omnivorous mammals, birds, reptiles, humans and all livestock may function as intermediate hosts for this disease (Valkiunas et al., 2011). This condition is called zoonosis which is defined as diseases and or infections naturally transmitted from other animals to humans (Acapovi et al., 2019). The occurrence of Trypanosomiasis in Africa largely depends on the presence of Tsetse flies. 
They infest 36 countries with a combined total area of between about 9 and 10 million $\mathrm{km}$, where close to 50 million cattle and tens of millions of small ruminants are at risk of being infected with Trypanosomes (FAO 2004). Africa Animal Trypanosome (AAT) and Human African Trypanosomiasis (HAT) have greatly affected settlements and economic developments in most African countries, particularly those south of the Sahara desert where it is transmitted mainly by Tsetse flies (Ny'ayo et al., 2005; Mamoudou et al., 2016). Tsetse flies are classified as follows; They belong to the class Insecta, subclass Pterygota, Order Diptera, Suborder Cycporrhapha and they belong to the genus Glossinidae, which is close to Muscoidae, from which they differ mainly by the adaptation of their mouthparts to blood sucking (Simarro et al., 2010). Their single genus (Glossina) includes three subgenera and 31 species and subspecies. These subgenera are subgenus; Nemorhina (also known as the Palpalis group), subgenus Glossina Sensu stricto (Morsitans group) and subgenus Austenina (Fusca group). They are the only known cyclical vector of Trypanosomes that go through a complete extrinsic growth cycle in their definitive host before being transported to vertebrates during their feeding (Simarro et al., 2010). Mamoudou et al. 2016, stress the fact that, Tabanus spp and Stomoxys spp are also capable of posing great challenges in the transmission of trypanosomiasis in Cameroon. This could also be the same case in The Gambia as little or no record is available on this speculation. However, all Tsetse fly species can possibly transmit Trypanosomes but relative prominence depends on the strength of their contacts with susceptible hosts. Tsetse flies are the main vectors of Trypanosomiasis and their existence pose a great threat to the survival of cattle in the country since their control in warthogs (a known host for Trypanosomes) is difficult and for religious reasons, the animal is inedible by the majority of Gambians (Snow et al., 1993). The Morsitans and Palpalis groups are mainly found in natural savannahs and riverine forest vegetation respectively, and are most essential species epidemiologically in causing Trypanosomiasis (Bouyer et al., 2019). The different Tsetse fly species are known to contribute to very different degrees in the transmission of human and animal African trypanosomes. Glossina fuscipes subspecies are mainly responsible for approximately $90 \%$ of human cases and together with Glossina palpalis subspecies, they are undoubtedly responsible for close to $100 \%$ of the cases of the Gambian form of the disease (T. brucei gambiense), which signifies approximately 97\% of human cases (Simarro et al., 2010; Bouyer et al., 2019). This is more fascinating considering that in the past, these two species complexes were considered to be subspecies (G. palpalis palpalis and G. palpalis fuscipes). In West Africa, the Palpalis group is presently responsible for most animal cases, this is due to its high resilience to anthropogenic changes, and with increasing human encroachment, and this situation is currently spreading to most Africa countries. The Fusca group forms 50\% of known species and subspecies. It is largely very sensitive to human encroachment specific to wild hosts, and generally little epidemiological impact, with the exception of Glossina brevipalpis in Southern Africa, which can be an efficient vector of AAT. Most of these species specifically that of Glossina medicorum is found in Burkina Faso and it has a distribution which is limited to specific kinds of vegetation do not feed at all on humans, and have practically no contact with livestock (Bouyer et al., 2019). This work seeks to show the havoc caused by trypanosomiasis and the urgency for more studies to investigate the patterns of transmission of the disease especially in the context of climate change in order to come up with even better program for the control of this zoonosis in The Gambia.

\section{PREVALENCE OF TRYPANOSOMIASIS IN CATTLE IN THE GAMBIA}

AAT affects many livestock species including cattle, sheep and goats. About 50 million cattle and 70 million sheep and goats are at risk for AAT and an estimated three million cattle die from the disease annually in Africa (Simarro et al., 2010). As the parasite maneuvers ways to avoid the animal's immune 
system, and in the absence of a suitable vaccine, surveillance, speedy diagnosis and treatment with existing drugs are not effective and vector control efforts will go a long way in decreasing the incidence of AAT (Oyibo et al., 2009; Zongo et al., 2016). AAT still remains by far the most devastating parasitic and neglected zoonotic disease in Africa, affecting both humans and livestock. Livestock rearing in Africa has affected the health, livelihoods and the environment of the peoples of the continent and in several regions of the continent, the demand for livestock products has exceeded domestic production. This demand is expected to be powered further by population growth, urbanization and income growth in many African nations (Simarro et al., 2010). In Senegal, many regions provide vast potential for agriculture and animal production, but AAT is one of the major limitations to the development of more effective livestock production systems (Ravel et al., 2015). Trypanosomiasis is known to be one of the most dynamic parasitic diseases distressing livestock production in The Gambia and equines are very susceptible (Starkey, 1990; Snow et al., 1996). Central River Region (CRR) of The Gambia is approximately 320 $\mathrm{km}$ from the coast. This area is mostly infested with the tsetse fly Glossina morsitans submorsitans, which is the major vector of Trypanosomiasis among animals and livestock in The Gambia and it is chiefly found in dry, canopied, savannah woodland. Glossina palpalis is also present, but are more limited to riverine vegetation. This region is ranked as an area of low to moderate Tsetse challenge (Rawlings et al., 1993). Over the past 30 years, high and medium Tsetse fly plague have been reported to occur in Kiang West and Niamina East districts respectively, but present Tsetse fly challenges and cattle Trypanosomiasis risks in these two districts needs to be updated for a better understanding of the current situation (ITC 2014).

The Indirect magnitudes of climate change also include the redistribution of vector species or prolonged seasonal transmission periods and spatial extension, as well as the vanishing of vector-borne diseases (Marselle,
2019). As vectors of AAT and HAT, the epidemiology of these diseases is determined largely by the abundance, density, and nurturing behaviors of these flies (Dumas et al., 1999). Trypanosomiasis has also been reported as a serious disease in domestic livestock which causes a significant negative impact on food production and economic development in many parts of the world, mostly in sub-Saharan Africa (Ayana et al., 2012). The Gambia is indisputably not an exception in the infestation and economic loses posed by Trypanosomiasis as it is in other nations within the sub-Sahara region. Agyemang et al. (1990) observed that, infected lactating N'dama cows with pathogenic trypanosomes, causes a lessening in their milk production. In financial terms, it was projected that the worsening in milk removed for human consumption due to trypanosome infections amounted to an average of $£ 1$ per month per cow. Cattle that were exposed to an increasing seasonal Tsetse challenge, trypanosome prevalence rates were highest in such animals under the most stressful physiological condition especially in lactating or pregnant cows and lowest in animals under the least physiological stress (dry-open). Furthermore, the average Packed Cell Volume (PCV) levels of uninfected cows were higher than those of infected cows of similar physiological status, and the average PCV values during the end of the dry season April June, were lower than those attained over the entire period (October-June) (Agyemang et al., 1990). This finding is also in agreement to that of (Mamoudou et al., 2016) who also explained that, the PCV values of infected cattle was lower as compared to that of the uninfected cattle in Cameroon. The distinct Tsetse distribution pattern in Bansang and Keneba shows that, animals were subjected to increasing levels of challenge. The higher Trypanosome prevalence in cattle observed in Bansang than in Keneba coincides with the higher Tsetse challenge at the previous area. Such a relationship between Tsetse challenge and Trypanosome prevalence in livestock has been reported for other study sites in the African Trypanotolerance Network (Agyemang et al., 1990). The major species 
causing Trypanosome infection in The Gambia are $T$. congolense and T. vivax and to a lesser degree $T$. brucei brucei. Mixed trypanosoma infection in some cattle was detected using molecular method including $T$. godfreyi and $T$. simiae or $T$. grayi which could not have been detected by buffy coat currently used in The Gambia (Demelza, 2018). In The Gambia, the incidence of Trypanosomes was more frequent in the last three months of the calendar year (October - December). Microscopic result indicated an incidence of $1.56 \%$ while's molecular analysis on the other hand showed a higher incidence of $12.5 \%$, and this made up of the following species; T. congolense kilifi (2.6\%), T. brucei brucei (0.52\%). T. congolense savannah/forest ( $0.52 \%), T$. vivax $(3.65 \%)$ and mixed infection was (5.21\%) Kargbo et al. (2018).

\section{TRENDS OF TSETSE INFECTATION IN THE GAMBIA}

A nation-wide study of the distribution of Tsetse flies Glossina morsitans submorsitans Newstead and G. palpalis gambiensis Vanderplank was carried out in The Gambia, during 1989-1990, using box traps at 1654 sites over an area of $10,000 \mathrm{~km}^{2}$. The overall distribution of Tsetse had changed little during the last 45 years. G. $m$. subtnorsitans was present in dry, canopied woodland in most parts of the country, but was absent from an area south of the River Gambia extending from the coast to some $100 \mathrm{~km}$ inland. G. p. gambiensis occurred in evergreen forest and woodland close to the coast, and in riparian habitats along the length of the River Gambia and its major tributaries (Rawlings et al., 1993). Tsetse flies are capable of living for about 50-100 days, but can live for up to 8 months in confinement. Their reproductive cycle is more analogous to that of mammals than a domestic fly: It actually has very few off springs which ranges from 5-10 and are carried by the ovoviviparous female in its uterus and nourished with the help of its milk glands. It laid its larvae every 10 days on the ground, where they rapidly metamorphose into pupae and then into imagoes without necessitating any extra food resources in the environment (Bouyer et al., 2019). An analysis of a thorough analysis of data on Tsetse abundance, infection rates and trypanosome prevalence in villagebased trypanotolerant cattle over 4 years period in The Gambia showed that seasonal patterns of abundance in Glossina morsitans infested areas were constant, and that the rates of trypanosome infection remained relatively invariable (Rawling et al., 1994). Trypanosomes were isolated in procyclic culture from the midgut of 36 Glossina morsitans submorsitans and G. palpalis gambiensis in The Gambia. Twenty-eight stocks $(78 \%)$ were identified using DNA probes specific for: (a) Trypanosoma (Nannomonas) congolense savannah type, (b) T. (N.) congolense riverine-forest type, (c) T. (N.) simiae and (d) Trypanozoon. T. simiae and savannah type $T$. congolense were found only in G.m. submorsitans while the riverine-forest type $T$. congolense was limited to populations of G.p. gambiensis from two isolated areas of relict forest; while one Trypanozoon stock was isolated from G.m. submorsitans. T. congolense accounted for only $17 \%$ of all Nannomonas infections, as recognized by dissection, in G.m. submorsitans. This reemphasizes the significance of unraveling infections below the sub-generic level when estimating challenge to domestic animals. $T$. simiae could not be distinguished from $T$. congolense by the arrangement of Trypanosomes in the fly proboscis. The eight stocks which were not identified by DNA probes were separated into two groups on the basis of hybridization with total DNA probes and the cycle of development in experimental tsetse and similar to insect forms of the crocodile parasite $\mathrm{T}$. grayi (McNamara and Snow, 1991). Tsetse populations are extensive in The Gambia and appear to be extremely strong despite changing climatic, demographic and environmental factors. These Tsetse populations are likely to continue to pose risk to humans and livestock productivity well into the future unless active control measures are put in place (Rawling et al., 1993). High or medium Tsetse challenge can be used to approximate the incidence of infection in susceptible cattle especially Zebu cattle, with a realistic degree of correctness, but only in a sure set of circumstances, that may include 
measurements such as cattle density and cattlefly contact (Claxton et al., 1992).

\section{INFECTION TRENDS IN SMALL RUMINANTS}

The impact of the $T$. congolense infection on the clinical and reproductive performance of the Djallonke rams was modest. It was only noticeable in negative weight variations, a higher rate of mounting refusals and on semen quality with some transient, but no substantial effects on mass motility, percentage live sperm cells and minor irregularities (Osaer et al., 1997). Overall Trypanosome prevalence was, higher in sheep than in goats but only significantly higher in the moderate risk area. Trypanosome infection reduced the PCV level significantly and seasonal effects indicated significantly lower PCV levels during the rains. Trypanosome infection significantly depressed weight gain in both species at times where infection rates were highest. In both species extensive lower weight gains were observed during the rainy season. Abortion rates were higher in goats than in sheep and highest in the high-risk site. Trypanosome infection in ewes in the high risk area increased lamb mortality significantly but had no effect on birth weights, nor on growth rates up to 4 months (Osaer et al., 1998; Ebene et al., 2016). The Djallonke sheep and West African Dwarf (WAD) goats are the main breeds in The Gambia and their trypanotolerant nature has been described as an ability to maintain production under infection (Osaer et al., 1998; Goossens et al., 1997.) In cattle as the capacity to limit reductions in PCV and regulate the level and duration of parasitaemia showed that these traits are positively genetically correlated with productivity (Osaer et al., 1998). In the moderate risk area, trypanosome infected animals of both species showed lower weight gain compared to the negative ones but were only significantly reduced in infected sheep during the losing periods. Similar to the high risk site, the difference in weight gain between periods (seasons) was Obvious (Osaer et al., 1998; Ebene et al., 2016). In a recent study by (Kargbo et al., 2018), Buffy Coat (BF) and Polymerase Chain Reaction (PCR) prevalence for both sheep and goats was $1.7 \%$ and $0 \%$ respectively in The Gambia. The above findings show that, sheep are more vulnerable to trypanosomiasis than goat, but however both organism are still at high risk of contracting trypanosomiasis in The Gambia since these animals are still expose to the vectors of the diseases.

\section{INFECTION TRENDS IN EQUINES}

The prevalence of indiscriminate spread of trypanosomiasis in working equine attending the Gambia Horse and Donkey Trust show in 2013 using PCR was 55.4\%. Trypanosoma congolense was most prevalent (47.0\%), followed by $T$. vivax (15.7\%) and $T$. brucei brucei $(2.4 \%)$. Mixed infections were common $(9.4 \%)$ and $T$. congolense/ T. vivax co-infection seemed to have the greatest clinical effect.

The spread of $T$. brucei brucei parasites to the central nervous system (CNS), confirmed by using immunohistochemistry and PCR, causes severe CNS dysfunction (Dhollander et al., 2006; Demelza, 2018). Currently, a reliable diagnosis of equine CNS needs post mortem samples. The loopmediated isothermal amplification (LAMP) assay was assessed for the diagnosis of equine $T$. brucei infection for the first time in both blood and cerebrospinal fluid (Demelza, 2018). The prevalence of $T$. brucei in the midgut of Glossina specimens was $1.7 \%$ and equine DNA was found in tsetse blood meals, providing evidence for ongoing relations between host, parasite and vector (Demelza, 2018). In another study in The Gambia, Dark Ground (DG) Microscopy results showed that the prevalence for August 1997 and the average monthly incidence for September 1997-1998 of trypanosome infections in horses (45.5 and $16 \%$, respectively) and this was significantly higher than in donkeys (6.2 and 9\%, respectively). Using Polymerase Chain Reaction (PCR), the number of detected cases was seven times higher than using the DG Microscopy. T. congolense was the most frequently observed species, followed by $T$. vivax and T. brucei. This clearly showed that horses are less infected with trypanosome as compared to donkeys (Faye et al., 2001). However, Pinchbeck et al. (2008) demonstrated that horses had a higher 
prevalence of trypanosome infection compared to donkeys with a prevalence rate of $91 \%$; an infection rate of $31 \%$ for Trypanosoma congolense Savannah, $87 \%$ for Trypanosoma vivax and 18\% for Trypanosoma brucei spp.

\section{IMPACT OF CLIMATE CHANGE ON THE DISTRIBUTION OF TSETSE FLIES IN THE GAMBIA}

Climate change has posed serious health impacts on both man and his animals, that range from direct effects such as progressive temperature rises from global warming, flooding or heat waves due to increased climate variability and extreme weather events; to indirect effects such as fluctuations in ecosystem services, food productivity or species distributions (Marselle et al., 2019). The global average temperature has increased by $0.78 \mathrm{C}$ during the past century, and is as well foreseen to rise by an extra 1.16.48C during the twenty-first century (IPCC, 2007). Increases in average global temperatures are likely to affect the epidemiology of vector-borne diseases by changing pathogen and vector development rates and generation times, changing the geographical distribution of vectors or their reservoir host populations, varying transmission patterns or modifying host vulnerability to infection (Patz et al., 2000; Gubler et al., 2001; Moore et al., 2012). Nevertheless, the relative repercussion of most vector borne disease (VBDs) is tremendously difficult to quantify, because in most countries there is usually no proper reporting system, poor diagnosis, and no surveillance or collated assessment of prevalence and or economic impact (Marselle et al., 2019). The Gambia has a Sahelian climate with a long dry season (November to May) and a short wet season (June to October). Rainfall usually ranges from 850 to $1200 \mathrm{~mm}$ and average temperatures range from 18 to $33{ }^{\circ} \mathrm{C}$. Relative humidity is about $68 \%$ along the coast and $41 \%$ inland during the dry season and generally over $70 \%$ throughout the country during the wet season (GOTG, 2003). The mean temperature nationwide is $25^{\circ} \mathrm{C}$. The Gambia has four main landscapes, namely; the floodplain, the colluvial slopes, the lower plateau and the upper plateau, with diverse soil types. The natural drainage is centered on the River
Gambia and its tributaries, namely Sandougou, Miniminyang, Baobolon, Sofaniama, and the Bintang Bolongs. The River Gambia, which covers $1,130 \mathrm{~km}$ long, originates from the Fouta Djallon highlands in Guinea. With its distinguishing Sudan Savanna woodland vegetation, The Gambia has the following main ecosystem types: forest ecosystems (close \& open woodland ecosystem), agricultural ecosystems (arable and rangeland ecosystems), marine and coastal ecosystems, inland water ecosystems (wetlands) and terrestrial ecosystems (tree/shrub savanna) (Gambia National Water Policy, 2006). These types of vegetation and climatic conditions provide the ambient environment for Tsetse flies to strive as these insects require $23{ }^{\circ} \mathrm{C}$ to $25{ }^{\circ} \mathrm{C}$ temperature and about $75 \%$ of relative humidity (Geiger et al., 2015). However, findings of the country's meteorological agency have shown a significant increase in Temperature during the last 60 years, some variability in rainfall and changes in the planting period for farmers during the rainy season as a result of late onset of rainfall (Gambia National Water Policy, 2006). Analysis of the average temperature in the Gambia has shown that, temperatures will increase between 3 and $4.5^{\circ} \mathrm{C}$, beginning with an increase in possible evapotranspiration by the year 2075. With respect to projected rainfall, General Circulation Model (GCM) outcomes vary generally between $-59 \%$ and $+29 \%$ of the 1951-1990 average of $850 \mathrm{~mm}$ per annum (GOTG, 2003). Regional GCM analyses comparing Surface Air Temperature (SAT) to those of the neighboring oceans projected annual rainfall to increase between $25 \%$ and $50 \%$ across the Sahara by the year 2080 (Haarsm et al., 2005). Although there is a general consensus that anthropogenic activities such as changes in land cover affect Sahel rainfall, little quantitative data exists that measure these influences at the local level, even though deforestation for firewood and charcoal production is a big problem in the Gambia and is happening at an unmanageable rate (GOTG 2003). With the above climate change projection by the GCM model, it has clearly shown that climate change and anthropogenic activities have had and would continue to have serious impact on the natural habitant of these flies and this may enable them 
to spread and adjust to other regions in The Gambia under prevailing environmental conditions.

\section{Conclusion}

It is imperative to lessen the emphasis on pathogen-targeted research, with much more research into the qualities of healthy animals, as well as physiological, behavioral and management systems that will promote the health of animals. Effective surveillance systems need to be established for most arthropod-borne diseases across The Gambia especially that of tsetse flies to allow a detailed risk analysis, including the evaluation of the prospective of spreading to other regions, villages or the introduction of unusual species and sub-specie of Tsetse. Trypanosomiasis still remains a life threatening infection for many livestock ruminants and equines in The Gambia. Morphological method of identifying Tsetse fly species has been used for decades in The Gambia but however, this method has some disadvantages especially its inability to distinguish between related species and sub species. The need to understand the pattern of transmission of Trypanosomiasis, the use of molecular tools to identify Tsetse flies and the use of recent climate models to explain and forecast the impact of climate change trends on Tsetse fly diversity and distribution needs to be documented in The Gambia.

\section{COMPETING INTERESTS}

The authors declare that they have no competing interests.

\section{AUTHORS' CONTRIBUTIONS}

AK conceived the idea for the work and wrote the proposal and RK assisted in editing the manuscript. Both parties gave final approval to the manuscript.

\section{ACKNOWLEDGEMENTS}

The authors appreciate the contribution and support of the Director of WASCALGraduate Research Program in Climate Change and Biodiversity, Universite Felix HouphouetBoigny, Ivory Coast, Professor Souleymane Konate, Abdourhimou Amadou Issoufou and Zainabou Dabre of the same address. We also want to appreciate the kind support and motivation given by Dr. N'golo A. Kone,
Nangui, Abrogoua University, Ivory Coast. Finally, we want to say a special thanks to the entire staff of West Africa Livestock Innovation Center, The Gambia especially the director Dr Arss Secka and Momodou Jeng for their understanding and cooperation in collection of articles for this write up.

\section{REFERENCES}

Acapovi GLY, Beugre JMV, Yapi CB, Sevidzem SL. 2019. Analysis of the situation of Bovine Cystic Echinococcosis at the Port-Bouët Abattoir: a retrospective study from 2008-2015. Int. J. Biol. Chem. Sci., 13(3): 1527-1533. DOI: https://dx.doi.org/10.4314/ijbcs.v13i3.25

Agyemang K, Dwinger RH, Jeannin P, Leperre P, Grieve AS, Bah ML, Little DA. 1990. Biological and economic impact of trypanosome infections on milk production in N'Dama cattle managed under village conditions in The Gambia. Animal Production, 50: 383389. DOI: $10.1017 /$ S0003356100004864.

Ayana M, Tesfaheywet Z, Getnet F. 2012. Across sectional study on the prevalence of bovine Trypanosomosis in Amhara region. Northwest Ethiopia. Livestock Research for Rural Development, 24(8).

DOI: http://www.lrrd.org/lrrd24/8/tesf24148.h tm.

Bouyer J, Carter NH, Batavia C, Nelson PMP. 2019. The Ethics of Eliminating Harmful Species: The Case of the Tsetse Fly. Forum, BioScience, 69(2): 125-135. DOI: 10.1093/biosci/biy155.

Claxton JR, Leoperro P, Rawlings P, Snow WF, Dwinger RH. 1992. Trypanosomiasis in cattle in Gambia: incidence, prevalence and Tsetse challenge. Acta Tropica, 50: 219-225. DOI: $10.1016 / \mathrm{s} 0304-4017(96) 01003-5$

Demelza K. 2018. Investigating Central Nervous System Trypanosomosis in working equids in The Gambia. $\mathrm{PhD}$ thesis, University of Glasgow. England. DOI:

https://eleanor.lib.gla.ac.uk/record=b331 5591

Dhollander S, Jallow A, Mbodge K, Kora S, Sanneh M, Gaye M, Bos J, Leak S, 
Berkvens D, Geerts S. 2006. Equine trypanosomosis in the Central River Division of The Gambia: a study of veterinary gate-clinic consultation records. Preventive Veterinary Medicine, 75 (3-4): 152-162. DOI: 10.1007\%2Fs10437-017-9245-3. DOI: http://dx.doi.org/10.4314/ijbcs.v10i4.11.

Dumas M, Bouteille B, Buguet A. 1999. Progress in Human African Trypanosomiasis, Sleeping Sickness. Springer-Verlag France. DOI: 10.1007/978-2-8178-0857-4.

Ebene NJ, Mingoas JP, Bayemi PH, Manchang TK, Mfopit MY, Onyali IO, Musongong GA Chiejina SN. 2016. Interaction between Trypanosoma brucei and Haemonchus contortus infection in West African Dwarf Goats. Int. J. Biol. Chem. Sci., 10(4): 1580-1589, 2016.

FAO. 2003. Strategic reviews of traps and targets for tsetse and African trypanosomiasis, 9-12. DOI: https://apps.who.int/iris/bitstream/handle /10665/69013/TDR_IDE_TRY_05.1.pdf

Faye D, de Almeida P, Goossens B, Osaer S, Ndao M, Berkvens D, Speybroeck N, Nieberding F, Geerts S. 2001. Prevalence and incidence of trypanosomosis in horses and donkeys in the Gambia. Veterinary Parasitology, 101(2): 101114. DOI: $\quad 10.1016 / \mathrm{s} 0304-$ 4017(01)00503-9.

Gambia National Water Policy. 2006. Water Resources Policy. Department of State for Fisheries and Water Resources. $19 \mathrm{pp}$.

https://www.gwp.org/globalassets/global /activities/impact-stories/furtherreading/water-resources-policy.pdf.

Geiger A, Ponton F, Simo G. 2015. Adult blood- feeding tsetse flies, trypanosomes, microbiota and fluctuating environment in Sub- Saharan African. ISME $J$, 9: 1496-1507.

DOI: https://doi.org/10.1038/ismej.2014.236.

Getachew A, Malone JB, Thomson AR. 2004. Geospatial for cost model for tsetse transmitted animal Trypanosomosis in Ethiopia. SINET, Ethio. J. Sci., 76: 93-94.

Goossens B, Osaer S, Ndao M, Kora S. 1997. Long term effects of an experimental infection with Trypanosoma congolense on clinical parameters and reproductive performance of trypanotolerant Djallonke ewes and West African Dwarf does. Res. Vet. Sci., 63: 169-173. DOI: 10.1016/0304-4017(94)90156-2

GOTG. 2003. Report of the Agricultural Census of The Gambia 2001/2002. D. o. P. D. D. o. S. f. A. (DOSA). Banjul, GOTG.

http://www.columbia.edu/ msj42/pdfs/C limateChangeDevelopmentGambia_smal 1.pdf

Gubler DJ, Reiter P, Ebi K L, Yap W, Nasci R, Patz JA. 2001. Climate variability and change in the United States: potential impacts on vector-androdent-borne diseases. Environ. Health Perspect.,109: 223-233. DOI: 10.2307/3435012.

Haarsm R, Selten F, Haarsma RJ, Selten FM, Weber SL, Kliphuis M. 2005. Sahel Rainfall variability and response to Greenhouse. Geophysical Research Letters, $\quad 32$ : $1-4 . \quad$ DOI: 10.1029/2005GL023232.

International Trypanotolerance Center. 2014. Annual Project Progress Report 2014 and outlook for 2015. http://www.walicwa.org/wpcontent/uploads/2015/09/ITCANNUAL-REPORT-FOR-2014-ANDOUTLOOK-FOR-2015.pdf

IPCC. 2007. Working Group III Fourth Assessment Report, IPCC. See Doi: http://www.ipcc.ch/publications_and_dat a/publications_and_data_reports.shtml.

Kargbo A. 2018. Incidence of Trypanosomiasis and molecular characterization of Trypanosome species in cattle in The Gambia. MSc thesis, Ahmadu Bello University, Zaria, Nigeria, p 10-50.

Ledoka MV. 2008. Molecular Characterization of Trypanosomes Commonly Found in Cattle, Wild animals and Tsetse fly in Kwazulu. PhD dissertation, KwaZuluNatal, South Africa, p 20-35.

Mamoudou A, Mbakou ALM, Ngungwa V, Sevidzem SL, Zoli AP, Achukwi MD. 2016. Preliminary assessment of bovine trypanosomiasis and its vectors in Santa, Bali and Bafut Sub-Divisions of 
the, North West Region, Cameroon. Int. J. Biol. Chem. Sci., 10(1): 1-12. DOI : http://dx.doi.org/10.4314/ijbcs.v10i1.1

Marselle MR, Stadler J, Korn H, Irvine KN, Bonn A. 2019. Biodiversity and

Health in the Face of Climate Change. Springer Nature: Switzerland AG. DOI: 10.1007/978-3-030-02318-8.

McNamara JJ, Snow WF. 1991. Improved identification of Nannomonas infections in tsetse flies from The Gambia. Acta Tropica, 48(1991): 127-136. DOI: 10.1016/0001-706X(90)90052-2

Moore S, Shrestha S, Tomlinson KW, Vuong H. 2012. Predicting the effect of climate change on African trypanosomiasis: integrating epidemiology with parasite and vector biology. J. R. Soc. Interface, 9: 817-830. DOI:10.1098/rsif.2011.0654

Ngayo MO, Njiru ZK, Kenya EU, Muluvi GM, Osir EO, Masiga DK. 2005. Detection of trypanosomes in small ruminants and pigs in western Kenya: important reservoirs in the epidemiology of sleeping sickness? Kinetoplastid Biology and Disease, 4: 5. DOI: https://doi.org/10.1186/1475-92924-5.

Nnko HJ, Ngonyoka A, Salekwa L, Estes AB, Hudson PJ, Gwakisa PS, Cattadori IM. 2016. Seasonal variation of tsetse fly species abundance and prevalence of trypanosomes in the Maasai Steppe, Tanzania, Journal of Vector Ecology, 42(1): 24-33. DOI: 10.1111/jvec.12236.

Osaer S, Goossens B, Jeffcoate I, Holmes P. 1998. Effect of Trypanosoma congolense and nutritional supplements in Djallonke ewes on live weight during pregnancy, post-partum weight, haematology parameters and lamb performance. Research in Veterinary Science, 65: 6569. DOI: https://doi.org/10.1016/S00345288 (98)90029-7

Osaer S, Goossens B, Kora S, Gaye M, Darboe L. 1999. Health and productivity of traditionally managed Djallonke sheep and West African dwarf goats under high and moderate trypanosomosis risk. Veterinary Parasitology, 82: 101-119. DOI: https://doi.org/10.1016/S0304-4017 (99)00011-4.
Osaer S, Goossens B, Sauveroche B, Dempfle L. 1997. Evaluation of the semen quality and reproductive performance of trypanotolerant Djallonke rams following an artificial infection with Trypanosoma congolense. Small Ruminant Research, 24: 213-222. DOI: https://doi.org/10.1016/S0921-4488 (96)00944-3

Oyibo WA, Agomo C, Olasosu OO, Teslim OO, Sanyaolu AO, Ajuluchuckwu J, Fagbenro-Beyioku, AF, Otigbuo I .2009. Human African trypanosomes: challenges posed to the human immune system. Int. J. Biol. Chem. Sci., 3(1): 156167.

Patz JA, Graczyk TK, Geller N, Vittor AY. 2000. Effects of environmental change on emerging parasitic diseases. Int. J. Parasitol., 30: 1395-1405. DOI: 10.1016/S0020-519(00)00141-7.

Pinchbeck GL, Morrison LJ, Tait A, Langford J, Meehan L, Jallow S, Jallow A, Christley RM. 2008. Trypanosomosis in The Gambia: prevalence in working horses and donkeys detected by whole genome amplification and PCR, and evidence for interactions between trypanosome species. BMC Veterinary Research, 4: $7 . \quad$ DOI: https://doi.org/10.1186/1746-6148-4-7.

Ravel S, Mediannikov O, Bossard G, Desquesnes M, Cunny G, Davoust BA. 2015. Study on Africa animal trypanosomosis in four areas of Senegal. Folia Parasitologica, 62: 044. DOI: https://doi.org/10.1017/S0007485300014 620.

Rawlings P, Ceesay ML, Wacher TJ, Snow WF. 1993. The distribution of tsetse flies Glossina morsitans submorsitans and Glossina palpalis gambiensis (Diptera: Glossinidae) in The Gambia and the application of survey results to tsetse and trypanosomiasis control. Bull. Ent. Res., 83: 625-632. DOI: https://doi.org/10.1017/S0007485300014 620

Rawlings P, Wacher TJ, Snow WI. 1994. Cattle-tsetse contact in relation to the daily activity patterns of Glossina morsitans submorsitans in The Gambia. 
Medical arid Veterinary Entomology, 8: 57-62.

Rogers DJ, Hay S, Packer MJ. 1996. Predicting the distribution of tsetse flies in West Africa using Temeral fourier processed meteorological satellite data. Annals of Tropical Medicine and Parasitological, 90(3): 225-241. DOI: http://dx.doi.org/10.4314/jab.v83i1.10

Shaida SS, Weber JS, Gbem TT, Ngomtcho $\mathrm{SCH}$, Musa UB, Achukwi MD, Mamman M, Ndams IS, Nok, JA, Kelm S. 2018. Diversity and phylogenetic relationships of Glossina populations in Nigeria and the Cameroonian border region. $B M C$ Microbiology, 18(1): 180. DOI: https://doi.org/10.1186/s12866-0181293-6.

Simarro PP, Cecchi G, Paone M, Franco JR, Diarra A, Ruiz JA, Fèvre EM, Courtin F, Mattioli RC, Jannin JG. 2010. The Atlas of human African trypanosomiasis: A contribution to global mapping of neglected tropical diseases. International Journal of Health Geographics, 9: 57. DOI: https://doi.org/10.1186/1476-072x9-57.

Snow WF, Wacher TJ, Rawlings P. 1996. Observations on the prevalence of trypanosomosis in small ruminants, equines and cattle, in relation to tsetse challenge, in The Gambia. Vet. Parasitol, 66: 1-1. DOI: https://doi.org/10.1016/s0304-4017 (96)01003-5.

Starkey P, 1990. Animal traction for agricultural development. In:
Proceedings of the Third Workshop of the West Africa Animal Traction Network, 7-12 July 1988, Saly, Senegal; Starkey P, Faye A (Eds). Technical Centre for Agricultural and Rural Co-operation, Ede-Wageningen: 90: 8-114.

Valkiunas G, Iezhova TA, Carlson JS, Sehgal RNM. 2011. Two new Trypanosoma species from African Birds, with notes on the taxonomy of avian Trypanosomes. $J$. Parasitol., 97(5): 924-930. DOI: 10.1645/GE-2796.1

Van M, Janssens PG, Magnus E, Moors A. 1973. Column separation and membrane filteration: A routine method for the detection of African trypanosomes in human blood. Ann. Soc. Belge med. Trop, 53(2): 109-112.

World Health Organization. 2013. Control and surveillance of human African trypanosomiasis: report of a WHO expert committee. (WHO technical report series). 984. https://apps.who.int/iris/handle/10665/95 732.

Zongo D, Bagayan M, Tiendrebeogo S, Drabo F, Ouedraogo H, Savadogo B, Bamba I, Yago- vienne F, Zhang Y and Poda JN. 2016. Assessment of schistosomiasis and intestinal helminths following mass drug administration in the Centre and Plateau Central regions of Burkina Faso. Int. J. Biol. Chem. Sci., 10(4): $\quad 1525-1533 . \quad$ DOI: http://dx.doi.org/10.4314/ijbcs.v10i4.6 